\title{
RESILIÊNCIA E POLÍTICA URBANA: AS ÁREAS DE RISCO DE INUNDAÇÃO EM ITAJAÍ-SC ${ }^{1}$
}

\author{
Suzane Concatto ${ }^{2}$ \\ Sérgio Torres Moraes ${ }^{3}$
}

DOI: 10.5752/P.2316-1752.2017v25n36p138

\begin{abstract}
Resumo
Desastres naturais que atingem as cidades, como enchentes e deslizamentos de encostas, têm reforçado a necessidade da elaboração de Planos Diretores que considerem a resiliência urbana, entendida como a capacidade de reagir e aprender com um evento natural extremo. Devido a uma ineficácia histórica no planejamento e gestão urbana e à forte desigualdade socioeconômica, as cidades brasileiras se encontram bastante vulneráveis a desastres ambientais. Desse modo, este estudo se propõe a salientar a necessidade de mudança de paradigmas e de uma melhor avalia-
\end{abstract}

\footnotetext{
1. Este artigo toma por base a dissertação de mestrado de Suzane Concatto, no Programa de Pós-graduação em Urbanismo, História e Arquitetura da Cidade (PGAU) da Universidade Federal de Santa Catarina (UFSC), sob orientação de Sergio Torres Moraes. 2. Arquiteta pela UNIVALI, mestre em Urbanismo, História e Arquitetura da Cidade da Universidade Federal de Santa Catarina (UFSC). Professora da Unisociesc- SC. E-mail: suzane.arquitetura@gmail.com.

3. Arquiteto Universidade Presbiteriana Mackenzie, Pós Doutorado na École Normale Superiore (ENS) de Paris. Professor adjunto da Universidade Federal de Santa Catarina. E-mail: sergiomoraes@arq.ufsc.br
} 
ção de prioridades nas tomadas de decisão na construção e gerenciamento do espaço urbano. Para esse objetivo, este artigo trata de um estudo de caso, a cidade de Itajaí em Santa Catarina, Brasil, em que são analisados mapas de inundações e seus diferentes zoneamentos.

Palavras-chave: Gestão urbana. Planejamento urbano. Resiliência urbana. Plano diretor. Inundações. 


\section{RESILIENCE AND URBAN POLICY: FLOOD RISK} AREAS IN ITAJAÍ-SC

\section{Abstract}

Natural disasters that affect cities, such as floods and landslides, have reinforced the need for the elaboration of Master Plans that consider urban resilience, understood as the capacity to react and learn with an extreme natural event. Due to a historical inefficiency in urban planning and management and strong socioeconomic inequality, Brazilian cities are very vulnerable to environmental disasters. Thus, this study aims to highlight the need for a paradigm shifts and a better assessment of priorities in decision making in the construction and management of urban space. For this purpose, this article frames a case study, the city of Itajaí in Santa Catarina, Brazil, where maps of floods and their different zoning are analyzed.

Keywords: Urban management. Urban planning. Urban resilience. Master plan. Floods.
RESILIENCIA Y POLIITICA URBANA: LAS ÁREAS DE RIESGO DE INUNDACIÓN EN ITAJAÍ-SC

\section{Resumen}

Los desastres naturales que afectan a las ciudades, como inundaciones y deslizamientos de laderas, han reforzado la necesidad de la elaboración de Planes Directores que consideren la resiliencia urbana, entendida como la capacidad de reaccionar y aprender con un evento natural extremo. Debido a una ineficacia histórica en la planificación y gestión urbana y la fuerte desigualdad socioeconómica, las ciudades brasileñas se encuentran bastante vulnerables a desastres ambientales. De este modo, este estudio se propone subrayar la necesidad de cambio de paradigmas y de una mejor evaluación de prioridades en las tomas de decisión en la construcción y gestión del espacio urbano. Para este objetivo este artículo trata de un estudio de caso, la ciudad de Itajaí en Santa Catarina, Brasil, donde se analizan mapas de inundaciones y sus diferentes zonificación.

Palabras-claves: Gestión urbana. Planificación urbana. Resiliencia urbana. Plan director. Inundaciones. 


\section{Introdução}

A grande desigualdade socioeconômica brasileira coloca a população de baixa renda como a mais vulnerável a riscos ambientais, pois a ocupação irregular de margens de rios e encostas, áreas fora do mercado legal de terras, acaba sendo suas únicas opções para moradia (MARICATO, 2001). Apesar do aumento da presença dessa população em áreas de risco ambiental nas últimas décadas, o poder público, em suas diferentes instâncias, ainda não logrou vencer a ineficácia histórica dos gerenciamentos urbanos na maior parte das cidades do país. Há tempos que os municípios buscam equacionar o desenvolvimento urbano e os fatores derivados dos diversos agentes produtores do espaço urbano (CORREA, 1989). Contudo, apenas nas últimas duas décadas, iniciou-se um processo político, legal e administrativo para uma necessária mudança nos paradigmas de urbanização e na avaliação das prioridades no planejamento, construção e gestão do espaço urbano.

Nesse contexto, a Lei Federal 10257/2001, conhecida como o Estatuto da Cidade, tem permitido construir uma dinâmica administrativa capaz de promover uma gestão da cidade mais integrada e participativa, que trata tanto as questões socioeconômicas quanto ambientais, possibilitando inclusive lidar com as áreas de fragilidade ambiental de maneira eficaz (BRASIL,2005). Apesar de sua abrangência, o Esta- 
tuto da Cidade não prescinde de outras leis que dão constitucionalidade para a gestão urbana, principalmente no tocante à questão das inundações. A Lei Federal 9433/1997, que institui a "bacia hidrográfica" como unidade territorial para implementação da Política Nacional de Recursos Hídricos e atuação do Sistema Nacional de Gerenciamento de Recursos Hídricos (BRASIL,1997), costitui uma peça fundamental para a composição legal da gestão urbana com considerações ambientais.

A grande dimensão da vulnerabilidade socioambiental das cidades brasileiras reforça a necessidade de incorporar a ideia de "resiliência urbana" como parâmetro de estruturação urbana. O conceito de "resiliência" tem se afirmado na última década nos estudos urbanos, de um modo geral, para designar a capacidade das cidades ou regiões de absorver os impactos causados por desastres naturais e evoluir. Holling (apud BALTAZAR, 2010) define a resiliência como uma "medida de persistência do sistema e sua competência para absorver mudanças e perturbações, mantendo ao mesmo tempo as relações entre populações ou variações de estado então estabelecido". Contudo, a ideia de emprestar o termo originado nas disciplinas de engenharia, ecologia e psicologia para sistemas territoriais tem suscitado debates em torno da própria polissemia do termo (REGEZZA-Zitt, 2012), mostrando que envolve questões mais profundas, como a construção e a produção de "ris- 
cos", níveis de vulnerabilidade e outros temas decorrentes da construção política e social do território.

Ainda que a "resiliência urbana" não seja tratada explicitamente dentro da lei do Estatuto da Cidade, acredita-se que as ferramentas urbanísticas disponíveis na lei podem ser eficazes e fundamentais para promovê-la. Neste artigo, portanto, sugere-se que a construção de Planos Diretores Participativos deve aumentar seu foco nas questões de redução dos riscos sociais e ambientais, da desigualdade socioeconômica e da promoção da resiliência, a partir da discussão de temas como uma possível redução planejada de densidade nas zonas urbanas sujeitas a riscos ambientais e reforço das centralidades em áreas seguras, entre outros.

Desse modo, é estudada a cidade de Itajaí, em Santa Catarina, Brasil, onde as inundações periódicas alteraram a dinâmica econômica da cidade e têm levado às diretrizes de planejamento considerações significativas sobre a problemática ambiental. Dessa forma, mapas de inundações e zoneamentos foram estudados a fim de compreender de que forma o planejamento e a gestão urbana têm lidado com a ocupação do solo em um contexto de atenção aos desastres ambientais e suas conseqüências socioeconômicas. 


\section{Áreas urbanas inundadas ou áreas alagáveis urbanizadas?}

Os assentamentos urbanos resultam de um processo histórico de disputas de terra, que, teoricamente, deveriam ser geridos pelo Estado. No entanto, na realidade brasileira, é comum a omissão do Estado, que permite que alguns atores urbanos acabem avançando sobre os princípios ambientais e de justiça social, reforçando a desigualdade socioeconômica na ocupação territorial (CORREA, 1989). O desenvolvimento urbano, alheio a princípios ambientais, colabora para o surgimento das inundações, que são o resultado da sobreposição do processo natural de um aumento da vazão do rio e da ocupação urbana. Com o aumento da urbanização, maiores são as mudanças no ciclo hidrológico e maiores as vulnerabilidades socioambientais.

Atualmente existem várias medidas já testadas para minimizar os efeitos socioambientais e econômicos das inundações nas zonas urbanas que podem ser mobilizadas e adaptadas a diferentes situações. As medidas ditas estruturais, como a construção de represas, reservatórios, modificação do rio, entre outros (TUCCl; BERTONI 2003), parecem prevalecer hoje como solução dos problemas de inundação na maior parte das administrações municipais. Essas obras estruturais e de implantação de curto prazo, entretanto, serão sempre insuficientes devido ao aumen- 
to da população, sendo evidente a necessidade de estudar em conjunto também o desenvolvimento de medidas não-estruturais de longo prazo, tais como alterações no zoneamento urbano, emissões de alerta e projetos de educação ambiental, entre outros (TUCCI; BERTONI 2003).

Neste estudo, portanto, defende-se a ideia da necessidade de investir em medidas não-estruturais, particularmente na construção de Planos Diretores que garantam uma ocupação do território que mire a melhora dos aspectos socioambientais relacionados com a questão dos ciclos hidrológicos em áreas urbanas. Para tanto, buscou-se entender o processo histórico de ocupação socioeconômica da cidade de Itajaí, a história das cheias, sua constituição ambiental, suas fragilidades e potencialidades, bem como analisar as propostas de ordenamento e desenvolvimento urbano a partir das proposições estabelecidas para as áreas alagáveis em seu Plano Diretor vigente.

\section{O Estatuto da Cidade e as áreas de vulnerabilidade a eventos naturais}

O Plano Diretor participativo construído dentro dos parâmetros do Estatuto da Cidade pode ser uma ferramenta essencial para promover a resiliência das cidades. Para tanto é necessária uma análise crítica dos processos de planejamento urbano vigentes para tornar essa ferramenta eficaz. 
Peças para o entendimento das dinâmicas hidrológicas deveriam ser fundamentais na construção dos Planos Diretores. Infelizmente, na maior parte deles, no Brasil, elas não são consideradas ou requeridas, como também não são considerados nos planos boa parte dos aspectos ambientais que poderiam aproximá-los da resiliência, como a drenagem urbana e a qualidade da água (TUCCI e BERTO$\mathrm{NI}, 2003)$.

A proposta avançada neste estudo vem, portanto, verificar a viabilidade de se planejar para a resiliência a partir da utilização de instrumentos do Estatuto da Cidade que possam induzir uma diminuição da ocupação e da densidade, paulatina e programada, de setores urbanos suscetíveis a inundações e deslizamentos e, em contrapartida, um aumento de densidades em setores menos vulneráveis da cidade, buscando, ao mesmo tempo, a diminuição da segregação socioespacial. ${ }^{4}$

Essa abordagem busca enfrentar alguns problemas específicos, como, por exemplo, áreas suscetíveis a cheias, onde os interesses do mercado imobiliário são muito fortes e

4. Entende-se que a análise dos zoneamentos focada na densidade populacional e comparada às inundações é somente uma possibilidade entre muitas outras para abordar o planejamento voltado à resiliência. Sabe-se que várias medidas, estruturais e não estruturais, devem ser consideradas e implementadas concomitantemente ao longo da bacia hidrográfica para resultar em uma eficaz prevenção contra inundações urbanas. 
difíceis de confrontar, ou lidar com os investimentos já realizados em infraestrutura (energia elétrica, redes de água e esgoto, etc.), nas áreas a terem sua densidade descontinuada. Esses e outros desafios do gerenciamento de densidades no espaço intraurbano devem encontrar base legal nos instrumentos urbanísticos do Estatuto da Cidade, que devem ser utilizados coerentemente em áreas específicas.

Para isso, é preciso apoiar o processo de planejamento em um estudo interdisciplinar que considere tanto o processo natural do regime do rio, o entendimento do solo e das condicionantes geofísicas e sociais que levam o local à sua vulnerabilidade como também as dinâmicas econômicas do município em questão. Além disso, é essencial que

se inclua no processo de planejamento a população que convive com as inundações, para chegar a uma agenda de prioridades compatível com as reais necessidades e capacidades econômicas, sociais e políticas da cidade.

\section{O Caso de Itajaí: o planejamento urbano e sua relação com o rio Itajaí-Açu}

O município de Itajaí está localizado na costa Atlântica da região sul do Brasil, às margens da rodovia BR-101 e a $90 \mathrm{~km}$ ao norte da capital do estado de Santa Catarina, Florianópolis. Sua população atual é de aproximadamente 212.615 habitantes (população estimada IBGE, 2017), 
numa área de $288 \mathrm{~km}^{2} ; 20 \%$ dessa área é urbana e $80 \%$, rural. A densidade média da área urbana do município é de aproximadamente 636,11 hab/ $/ \mathrm{Km}^{2}$ (IBGE, 2017).

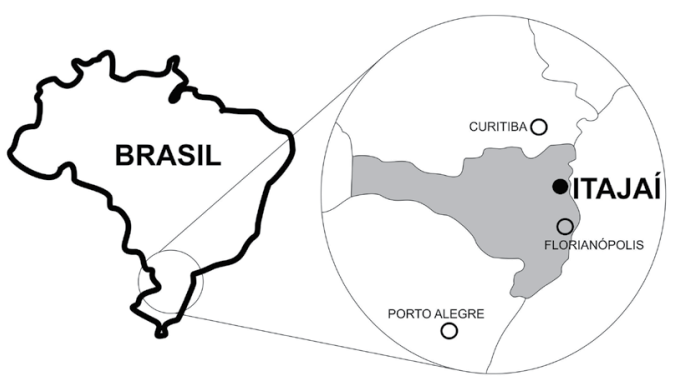

Figura 1 | Localização de Itajaí. Fonte: IBGE Mapas (2015) modificado pelos autores.

Migrantes luso-açorianos formaram o primeiro grupo de moradores da cidade de Itajaí, que foi efetivamente emancipada em 1860. A cidade faz parte da bacia hidrográfica do rio Itajaí-Açu e se insere na microrregião da Associação dos Municípios da Foz do Rio Itajaí-Açu (AMFRI). O município destaca-se por ser o mais importante centro portuário do estado de Santa Catarina, tendo sua economia sustentada pelas atividades portuárias, pelo comércio atacadista de combustível, pela pesca e pelo setor de produção industrial. O Rio Itajaí-Açu tem grande importância para o município, uma vez que sua navegabilidade possibilita o desen- 
volvimento industrial e comercial da região. Contudo, em função das condições hídricas e geológicas, há o favorecimento de frequentes inundações em suas áreas urbanas e rurais (PREFEITURA MUNICIPAL DE ITAJAI, 2017a).

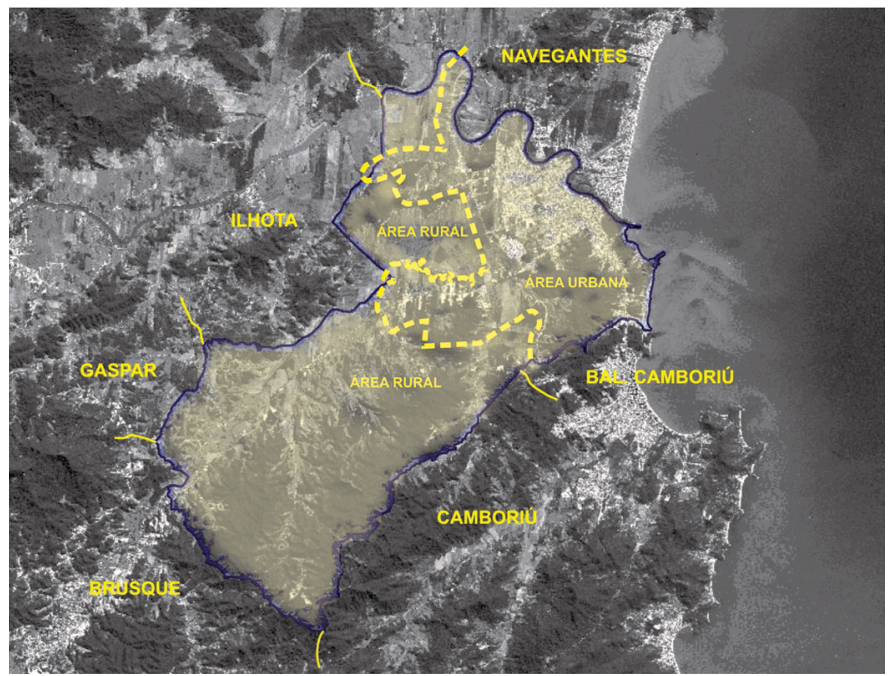

Figura 2 | Limites do município de Itajaí.

Fonte: Google Earth modificado pelos autores.

Existem relatos de inundações na cidade desde 1851 e as mais recentes aconteceram nos anos de 2001, 2008 e 2011. Frank e Sevegnani (2009) apontam que esses eventos não são excepcionais; são eventos recorrentes e a ocupação 
urbana tem papel determinante nas ocorrências das inundações. Importante notar que a inundação de 2008 ocupou quase toda a área urbana de Itajaí, conforme se verifica na figura 3.

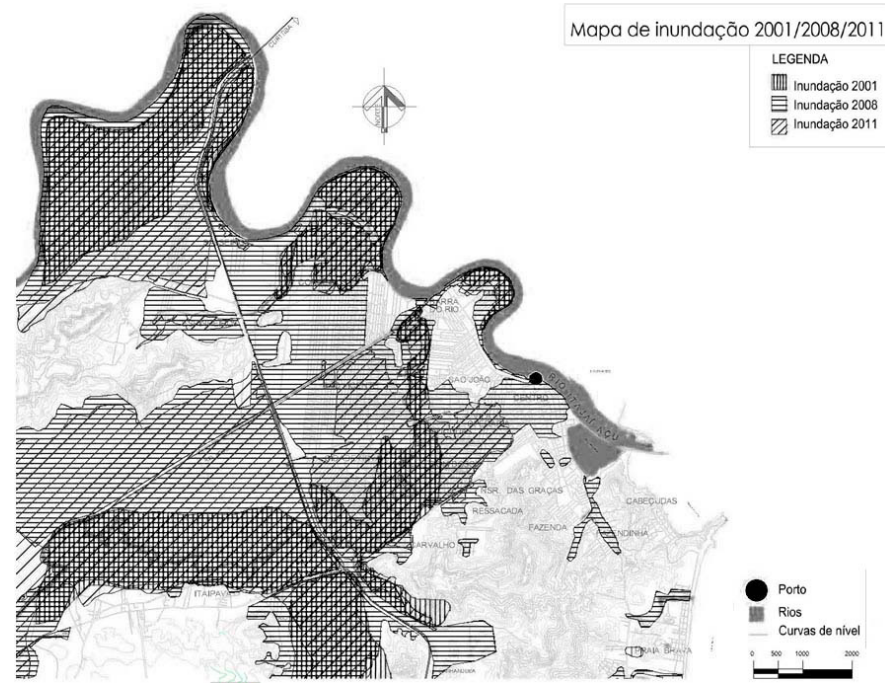

Figura 3 | Inundações 2001/2008 e 2011. Fonte: Elaborado pelos autores, 2014.

O primeiro Plano Diretor de Itajaí foi elaborado em 1971. Antes disso, o desenvolvimento urbano era conduzido por iniciativas públicas, que se limitavam a medidas de reestruturação espacial, de acordo com as demandas premen- 
tes e de forma espacialmente fragmentada. Esse plano de caráter essencialmente técnico-funcionalista propõe instrumentos de planejamento e parâmetros edilícios supostamente suficientes para orientar o desenvolvimento da cidade (SANTOS, 2008), de acordo com os parâmetros adotados nacionalmente na época para elaboração dos chamados Planos de Desenvolvimento Integrados (PDDI).

Apesar disso, nem as revisões do zoneamento da cidade na década de 1980 nem as diferentes leis complementares para regulação do uso e ocupação do solo editadas na década de 1990 parecem ter sido capazes de dar coerência a uma urbanização sincronizada com a realidade ribeirinha. Apenas em 2006, com a obrigatoriedade da elaboração de planos participativos, trazida pelo Estatuto da Cidade, Itajaí começa a desenhar diretrizes que explicitam uma preocupação socioambiental.

$\mathrm{Na}$ construção desse plano, a participação de organizações, tais como Agenda 21, Gerenciamento Costeiro, Projeto Orla e do Comitê da Bacia do Rio Itajaí-Açu, colaborou para ampliar o caráter ambiental do plano, ainda que posteriormente excluídas dos debates (SANTOS, 2008). Nesse sentido, ao observar os gráficos temáticos das reuniões da Conferência da Cidade reportada por Santos (2008), nota-se a total ausência de discussões sobre as recorrentes enchentes da cidade. 
Em 2012, a elaboração do novo Plano Diretor da cidade traz uma abordagem mais complexa da questão das enchentes, uma vez que a ampliação do debate resultante da grande cheia de 2008 ajudou sobremaneira na incorporação de elementos socioambientais mais coerentes. Embora controverso em tópicos de caráter ambiental conflituosos com os anseios do mercado imobiliário, esse plano é notadamente mais avançado que os precedentes, ao tratar a relação da urbanização com as áreas ribeirinhas.

Ali, por exemplo, foram priorizadas algumas áreas como sendo aquelas de maior vulnerabilidade e, portanto, não suscetíveis ao adensamento, como é o caso da ZPA $3,{ }^{5}$ definida como um parque alagável. Outras áreas, mais ao norte da cidade, receberam um caráter mais industrial/pesqueiro e de baixa densidade habitacional, o que contribui para a sua resiliência em casos de inundação.

\section{Análises e diretrizes para uma possível resiliência urbana}

A verificação dos mapas de densidade do Censo (IBGE, 2010) e a proposta de densidade a partir do zoneamento de 2012, que está em vigor atualmente (PREFEITURA MUNICIPAL DE ITAJAI, 2012), são o ponto inicial 
desta análise. Em uma etapa seguinte, a sobreposição dos mapas de inundações da área urbana (comum aos últimos três anos de ocorrência de inundação) tem como objetivo visualizar as propostas de planejamento urbano em relação ao adensamento populacional e a consideração ou não das inundações.

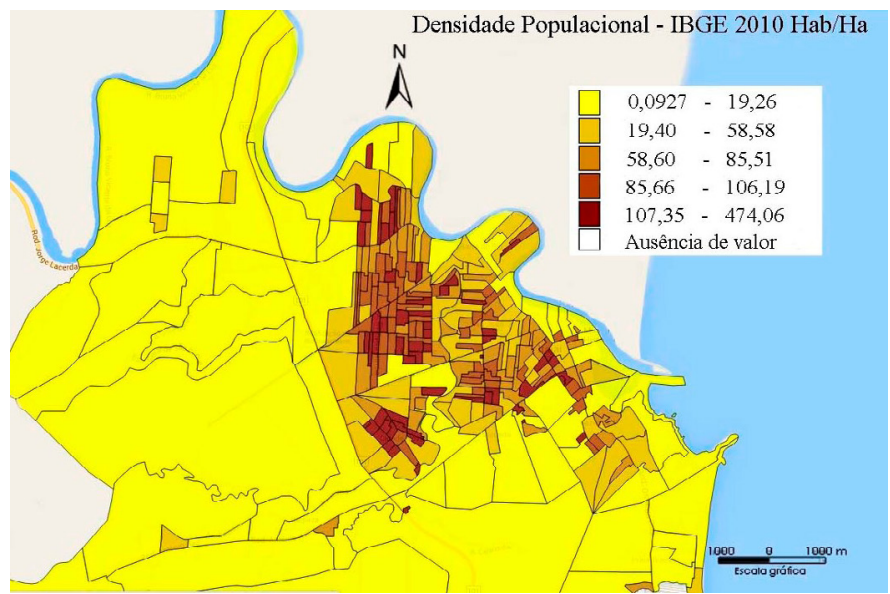

Figura 4 | Densidade populacional IBGE 2010

Fonte: Elaborado pelos autores, 2014 


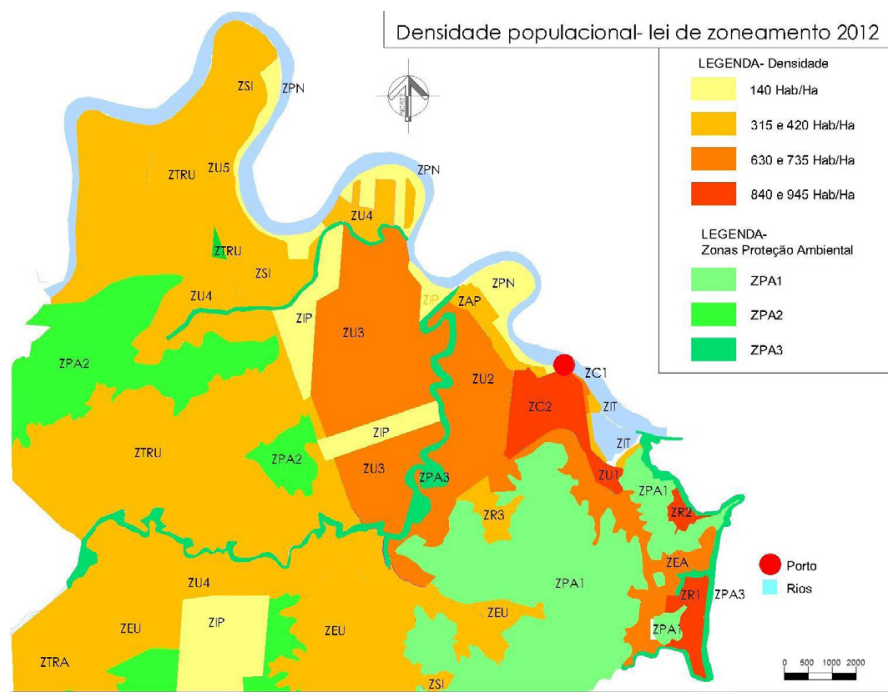

Figura 5 | Densidade populacional máxima pela lei de zoneamento de 2012. Fonte: Elaborado pelos autores, 2014.

O mapa de densidade baseado no zoneamento de 2012 aponta claramente uma intenção de densificação no sentido leste-oeste, partindo do centro da cidade (ZC2), ainda que a densidade aferida em 2010 (IBGE, 2010) mostre uma grande concentração populacional nas áreas mais a oeste do porto. A observação dessas informações leva a especular a possibilidade ou não de novas centralidades urbanas surgirem nessas áreas. Entende-se, assim, que o plano diretor de 2012 não apresenta incentivos efetivos para a densificação pretendida e parece mais certo a manutenção 
das tendências atuais de desenvolvimento urbano.

O mapa a seguir mostra a sobreposição da densidade projetada pelo zoneamento de 2012, com o mapa de inundação comum aos três anos (2001/2008 e 2011), ou seja, as áreas que alagam com maior frequência.

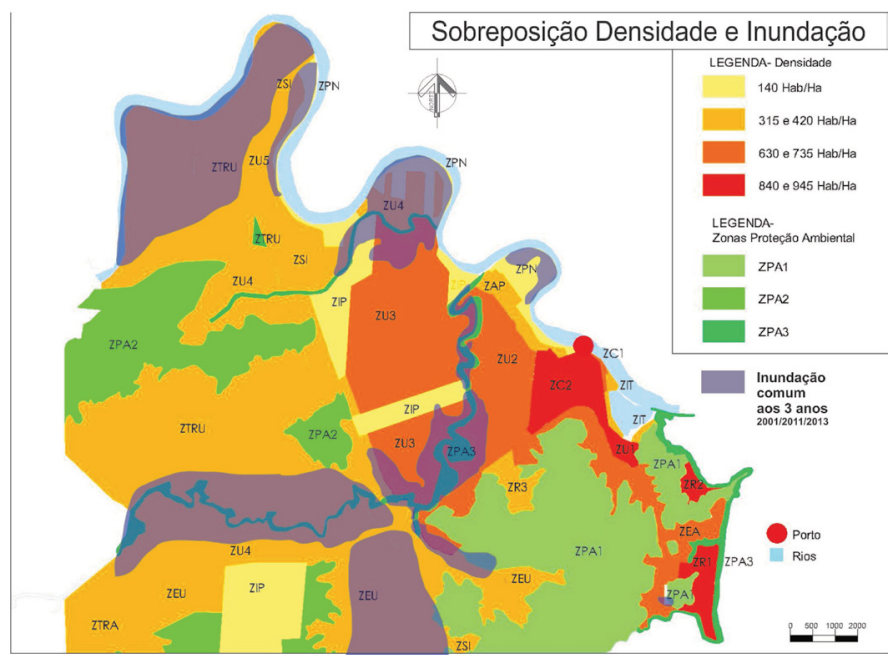

Figura 6 | Sobreposição densidade e inundação. Fonte: Densidade populacional máxima pela lei de zoneamento de 2012. Fonte: Elaborado pelos autores, 2014. 
A partir dessa sobreposição, é possível constatar que a proposta do Plano Diretor de 2012 deu atenção a áreas de vulnerabilidade, prevenindo adensamentos e demarcando parques em zonas alagáveis. Sem dúvida, a demarcação de uma zona que considere as cheias é bem-vinda; contudo, uma efetiva proposta de resiliência do plano poderia definir uma demarcação mais ampla para abranger toda a área de inundação de maior frequência.

Por outro lado, muitas das áreas que foram pensadas como de "alta densidade" estão em áreas bastante vulneráveis, como trechos da ZU2 e ZU3, o que traz incoerência aos critérios de planejamento das densidades expressos, quando analisados da perspectiva das inundações e da resiliência.

Cientes da complexidade dos fatores que influem no desenvolvimento urbano e na diversidade dos agentes produtores do espaço urbano, optou-se, como já mencionado, pela análise voltada às tendências de densificação, a qual, acredita-se, pode ser um fator determinante nas relações urbanas capitalistas e/ou especulativas. Assim, foi proposto desenhar um mapa de densidades que pretende colaborar para uma discussão voltada a equacionar o desenvolvimento da cidade de Itajaí e seus recorrentes problemas de inundação. A proposta aqui delineada tem claramente um viés focado nas questões ambientais e na legislação urbanística definida no Estatuto da Cidade. Sua elaboração parte da 
identificação das áreas mais vulneráveis e das áreas que nunca alagam para sugerir uma redistribuição de densidades populacionais em um horizonte de 50 anos. Este mapa sugere que as áreas que nunca foram atingidas por inundações devem conter as densidades mais altas (vermelho). Para as áreas de maior vulnerabilidade, deve-se incentivar um esvaziamento e as áreas que alagam eventualmente, pensadas para abrigar densidades médias e tipologias habitacionais diferenciadas, possibilitando a fixação de menos pessoas em áreas vulneráveis, fazendo com que aumente a resiliência do local.

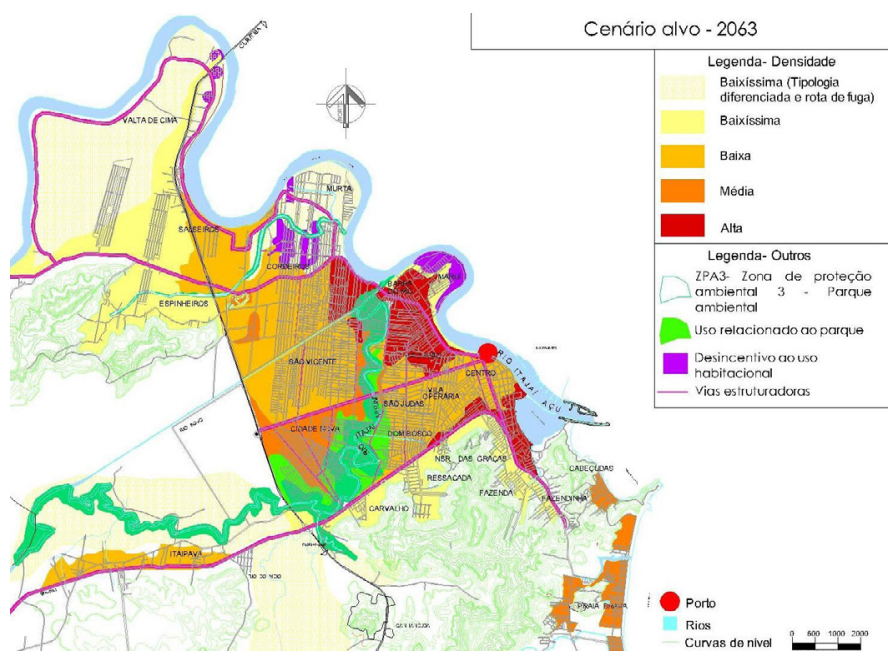

Figura 7 | Cenário alvo.

Fonte: Elaborado pelos autores, 2014. 
Conforme mencionado anteriormente, uma zona de proteção ambiental (ZPA3) foi definida no plano. Não obstante, sugere-se torná-la maior para coincidir com a área de inundação frequente. Essa área deve ser a mais restritiva para usos urbanos, uma vez que é a mais vulnerável ao alagamento. $\mathrm{O}$ uso dessa área como parque urbano deve dar área de apoio para o ZPA3, permitindo usos comerciais e serviços. Devido à sua vulnerabilidade, residências são apenas toleradas. Já as áreas de alta vulnerabilidade de inundação não devem ser suscetíveis ao uso residencial. Usos menos sujeitos a danos devem ser promovidos ali, como usos sociais/lazer, que irão colaborar com a manutenção da área. Em tempos de seca, o uso do espaço ocorre normalmente. Em caso de inundações, as áreas se tornam grandes bacias de contenção de águas.

De um modo geral, entende-se que os instrumentos do Estatuto da Cidade podem ser efetivos para uma reorganização do uso e ocupação orientados para a resiliência. Instrumentos tais como a transferência do potencial construtivo ou as "Operações Urbanas Consorciadas" podem colaborar efetivamente para a redução da densidade em áreas de risco. A presente proposta de distribuição da população pode ser garantida a partir do uso de alguns instrumentos do Estatuto da Cidade, como mostrado no Quadro 1. 


\begin{tabular}{|c|c|c|}
\hline INSTRUMENTO & OBJETIVO & JUSTIFICATIVA \\
\hline 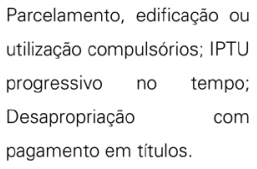 & $\begin{array}{l}\text { Aumentar a oferta de terras em } \\
\text { regiōes centrais. }\end{array}$ & $\begin{array}{l}\text { Utilizar o instrumento nas áreas } \\
\text { onde se desejam altas } \\
\text { densidades. }\end{array}$ \\
\hline $\begin{array}{l}\text { Outorga onerosa do direito } \\
\text { de construir ou solo criado. }\end{array}$ & $\begin{array}{l}\text { Lidar com o interesse imobiliário e } \\
\text { arrecadar verba para } \\
\text { investimentos. O plano diretor } \\
\text { poderá definir áreas nas quais o } \\
\text { direito de construir poderá ser } \\
\text { exercido acima do coeficiente de } \\
\text { aproveitamento básico. }\end{array}$ & $\begin{array}{l}\text { Aplicar em áreas onde o interesse } \\
\text { imobiliário for maior, próximas ao } \\
\text { parque ZPA3, por exemplo, e } \\
\text { onde se desejam altas } \\
\text { densidades. }\end{array}$ \\
\hline $\begin{array}{l}\text { Transferência do direito de } \\
\text { construir. }\end{array}$ & $\begin{array}{l}\text { Viabilizar a preservação de áreas de } \\
\text { importância ambiental. É possivel } \\
\text { transferir o potencial construtivo de } \\
\text { uma área para outra pré- } \\
\text { estabelecida, ou negociá-las no } \\
\text { mercado imobiliário. }\end{array}$ & $\begin{array}{l}\text { Deslocar populaçōes de área } \\
\text { vulnerável e facilitar que } \\
\text { construam suas habitações em } \\
\text { outras áreas. }\end{array}$ \\
\hline $\begin{array}{l}\text { Operação } \\
\text { consorciada. }\end{array}$ & $\begin{array}{l}\text { Viabilizar intervenções de grande } \\
\text { escala com parceria público- } \\
\text { privada. }\end{array}$ & $\begin{array}{l}\text { Viabilizar a implantação do parque } \\
\text { alagável (ZPA3) e outras } \\
\text { estruturas necessárias para } \\
\text { melhorar a resiliência. }\end{array}$ \\
\hline Direito de preempção. & $\begin{array}{l}\text { Dar prioridade à aquisição por parte } \\
\text { do poder público, de áreas de seu } \\
\text { interesse para realização de } \\
\text { projetos específicos. }\end{array}$ & $\begin{array}{l}\text { Permitir que a prefeitura tenha } \\
\text { prioridade na compra de lotes } \\
\text { onde se pretende fazer uma } \\
\text { intervenção futura, especialmente } \\
\text { àquelas destinadas a parque e } \\
\text { contenção de águas. }\end{array}$ \\
\hline ZEIS & $\begin{array}{l}\text { Reserva de terrenos para moradias } \\
\text { sociais. }\end{array}$ & $\begin{array}{l}\text { Reservar terras urbanas para ZEIS } \\
\text { em áreas menos vulneráveis, } \\
\text { centrais e de alta densidade. }\end{array}$ \\
\hline
\end{tabular}

Quadro 1 | Instrumentos do Estatuto da Cidade utilizados. Fonte: Elaborado pelos autores, 2014. 
Como já citado, a construção de um cenário que prevê o esvaziamento de áreas já povoadas traz vários complicadores, envolvendo questões econômicas relacionadas principalmente com o valor da terra, e de infraestrutura, além de problemas sociais. Deve-se evitar, portanto, que essas áreas não sejam abandonadas ou percam vitalidade urbana, provocando aumento da criminalidade e apropriações indevidas. Um novo centro com maior densidade deve possuir um desenho urbano complexo que supra todas as necessidades dessa nova concentração populacional.

Esse cenário parece factível para um horizonte de 50 anos. Acredita-se que, com administrações públicas sérias, que usem com propriedade os instrumentos urbanos disponíveis na legislação brasileira, é possível pensar a cidade em longo prazo buscando prevenção, melhorando as relações socioeconômicas e ambientais e fazendo com isso que a população conviva com as inundações de forma mais adequada, saindo do ciclo de remediações improvisadas e grandes investimentos em obras estruturais (CONCATTO, 2014).

\section{Conclusões}

Particularmente no Brasil, a complexa dinâmica de produção do espaço antrópico é fruto de um processo histórico de conflitos de poder em que a lógica do mercado imobi- 
liário privilegia as classes de médias e altas rendas com a ocupação de áreas com melhores infraestruturas. Romper com essa desigualdade socioeconômica expressa na ocupação do território sempre foi um dos objetivos do Estatuto da Cidade, que é um instrumento dinâmico e contemporâneo para a gestão urbana.

O Estatuto da Cidade possui apenas 17 anos e é muito recente se comparado ao processo histórico de ocupação urbana no Brasil, que ocorreu em sua maior parte sem planejamento ou com planejamento desequilibrado com foco apenas no mercado imobiliário. Portanto há muito que evoluir para que os planos diretores respeitem efetivamente as questões ambientais e as relações do ser humano e a natureza. Desse modo, este estudo buscou salientar que é possível o uso de instrumentos urbanísticos legais (Estatuto da Cidade) para promover a resiliência em cidades vulneráveis a desastres ambientais.

Além do Estatuto da Cidade, o Brasil possui uma legislação ambiental e urbana bastante eficiente, inclusive no que tange à ocupação das áreas de fragilidade ambiental e da preservação do patrimônio cultural e ambiental. Contudo, ainda há certa resistência quanto à relevância da questão ambiental nos processos de planejamento urbano. A introdução de aspectos relacionados ao conceito de "resiliência" nesses processos ainda enfrenta barreiras políticas 
difíceis de serem quebradas, em uma realidade na qual a visibilidade política-eleitoral ainda se calca em obras estruturais que podem ser visualizadas e onde o mercado imobiliário impõe regras para a ocupação do território focada no capital.

Neste artigo, a construção de um cenário a partir de séries históricas das inundações e dos dados de densidade e infraestrutura permitiu avaliar e entender as propostas atuais de gestão territorial da cidade de Itajaí e indicar diretrizes alternativas para uma gestão mais complexa, que inclua preocupações ambientais e sociais mais contundentes na construção de uma cidade com mais qualidade de vida, mais justa de forma social e resiliente.

\section{Referências}

BALTAZAR, A. P. Sobre a resiliência dos sistemas urbanos: devem eles ser resilientes e são eles realmente sistemas? V!RUS. n. 3. Trad. Biaggioni, B.; D'Andréa, A. São Carlos: Nomads.usp, 2010. Disponível em: http://www.nomads.usp.br/virus/virus03/invited/layout. php?item=1\&lang=pt. Acesso em: 10 fev. 2014.

BRASIL. Lei Federal 9433/97, de 8 de janeiro de 1997. Política Nacional de Recursos Hídricos, cria o Sistema Nacional de Gerenciamento de Recursos Hídricos. Diário Oficial da União, Brasília, 8 de jan. 1997.

BRASIL. Lei Federal 10.257/01, de 10 de julho de 2001. Regulamenta os arts. 182 e 183 da Constituição Federal, estabelece diretrizes gerais da política urbana e dá outras providências. Diário Oficial da União, Brasília, 10 jul. 2001.

CONCATTO, Suzane. O espaço urbano inundado: as relações entre a dinâmica de produção do espaço urbano e a convivência com o rio 
em Itajaí/SC. 2014. 246 p.

CORREA, Roberto L. O espaço urbano. São Paulo: Editora Ática, 1989. 94 p.

INSTITUTO BRASILEIRO DE GEORAFIA E ESTATÍSTICA. Cidade de Itajaí. Disponível em: https://cidades.ibge.gov.br/brasil/sc/itajai/panorama Acesso em: 23 out. 2017.

INSTITUTO BRASILEIRO DE GEORAFIA E ESTATÍSTICA. Mapas.

Disponível em: http://geoftp.ibge.gov.br/mapas_tematicos/fisico/brasil_fisico.pdf. Acesso em: 05 out. 2015.

MARICATO, Erminia. Brasil, cidades: alternativas para a crise urbana. 2. ed. Petrópolis, RJ: Vozes, 2001. 204 p.

PREFEITURA MUNICIPAL DE ITAJAI. Itajaí - Distâncias. Disponível em: http://www.itajai.sc.gov.br/distancias.php. Acesso em: 1 out. 2017.

PREFEITURA MUNICIPAL DE ITAJAI. Itajaí - Histórico. Disponível em: <http://www.itajai.sc.gov.br/historia.php.> Acesso em: 1 out. 2017.

REGHEZZA-ZITT, Magali. Utiliser la polysémie de la résilience pour comprendre les différentes approches du risque et leur possible articulation, EchoGéo [En ligne], Disponível em: http://echogeo.revues. org/13401; DOI : 10.4000/echogeo.13401. Acesso em: 10 jul. 2013.

SANTOS, Samuel S. dos. Plano diretor de Itajaí: do desenho da participação à participação sem desenho. 2008. Dissertação (Mestrado) - Programa de Pós-Graduação em Geografia da Universidade Federal de Santa Catarina, Florianópolis.

SILVA, José Ferreira da. As enchentes no Vale do Itajaí. Blumenau: Fundação Casa Dr. Blumenau, 1975. 48p.

TUCCl, Carlos E. M; BERTONI, Juan Carlos. Inundações urbanas na América do Sul. Porto Alegre: ABRH, 2003. 428p. 